\title{
SEMANA DO MEIO AMBIENTE COMO UMA PROPOSTA INTERDISCIPLINAR PARA INSERÇÃO DA EDUCAÇÃO AMBIENTAL NA ESCOLA
}

\author{
Betânia Cristina Guilherme1; Everaldo Nunes de Farias Filho²; Rhaelly Eduarda de \\ Lima Silva3; Valentina Manoel dos Santos ${ }^{4}$.
}

\section{DOI: https://doi.org/10.31692/2358-9728.VICOINTERPDVL.2019.0171}

\section{RESUMO}

Atualmente, percebe-se o crescente alerta mundial quanto a assuntos de cunho ambiental. Para um maior impacto, no dia 5 de junho é comemorado o dia Mundial do Meio Ambiente, com intenção de ampliar o conhecimento populacional acerca dos recursos naturais e cuidados com o meio de forma a manter o ambiente mais sustentável como também sensibilizar sobre a preservação do mesmo. Dessa forma, foi planejada uma programação com ações de cunho interdisciplinar e didático com a temática de meio ambiente e correlatos, desenvolvida pelos bolsistas do Programa Institucional de Bolsa de Iniciação à docência PIBID-BIOLOGIA juntamente com o professor supervisor, que ocorreu no Colégio Agrícola Dom Agostinho Ikas - CODAI com objetivo de discutir com os estudantes temáticas relacionadas ao meio ambiente. O conteúdo foi trabalhado durante a semana do meio ambiente, com uma abordagem CTSA (ciência, tecnologia, sociedade e ambiente) por meio de palestras, rodas de conversas, oficinas, mesas redondas, experimentos e documentários, foram tratadas problemáticas atuais que envolvem a conservação e o cuidado com o meio ambiente adjunto a educação ambiental e em conjunto com a comunidade escolar. Nessa perspectiva entendemos a importância de destacar a temática de preservação do meio ambiente diante das defasagens de ensino encontradas no ensino básico, sendo necessária intensificar a abordagem de tal conteúdo de formas e perspectivas diferenciadas.

Palavras-chaves: sustentabilidade; educação ambiental; interdisciplinaridade, CTSA. 


\section{INTRODUÇÃO}

Assuntos de cunho ambiental como valorização, preservação e conservação dos recursos naturais têm sido crescente nos últimos anos. A ciência, tecnologia e industrialização avançam causando a degradação do ambiente, mas um olhar crítico de visualização a longo prazo prevê um desequilíbrio ambiental que possibilita a extinção da vida caso a forma irresponsável de cuidar do meio ambiente permaneça. Sendo assim, a proposta de educação ambiental nas escolas visa a conscientização e formação de cidadãos que tornam o meio sustentável (ROOS,2012).

No entanto, apesar de alertas quanto às possíveis consequências provenientes da ação humana no meio ambiente, poucas são as mudanças e consequentemente, os avanços. Nesse sentido, a sociedade que busca qualidade de vida precisa de Educação Ambiental (EA) (PELICIONI, 1998).

Visando ampliar os olhares da população, no dia 5 de junho é comemorado o dia do Meio Ambiente. O contato com informações acerca das formas de degradação do ambiente causadas pelos ser humano no dia a dia é uma forma de reflexão e mobilização de ações para o cuidado com o ambiente em todos os seus aspectos (biológicos, social, cultural).

A participação da instituição escolar desempenha um papel fundamental como um elo entre o estudante e o conhecimento, ou seja, a educação ambiental deve ocupar um espaço importante nos currículos escolares. Dessa forma, o ensino de ciências naturais desempenha um papel fundamental quando se trata da temática de educação ambiental sendo caracterizada como processo educativo que visa tornar cidadãos críticos e participativos no que se refere às questões ambientais e manutenção da qualidade de vida em diversos ambientes.

Portanto, o presente trabalho tem por objetivo discorrer acerca da importância da interdisciplinaridade aplicada à temática da EA por meio de ações de cunho socioambiental realizadas na semana do meio ambiente. 


\section{A INTERDISCIPLINARIDADE COMO FERRAMENTA DE INTEGRAÇÃO PARA INSERÇÃO DA EDUCAÇÃO AMBIENTAL}

A interdisciplinaridade visa a totalidade onde a integração de disciplinas promove um ensino mais enfático, dinâmico estimulando o senso crítico do estudante, pois essa metodologia visa integrar os conteúdos à realidade de vida, ao cotidiano do aluno (CONRADO, 2017). Dessa forma, o estudante pode relacionar os conteúdos e problemáticas ambientais tendo em vista as aplicações de suas ações no meio.

Quanto à temática interdisciplinar Coimbra 2004, destaca a importância da mesma e sua relação com meio ambiente:

A ação interdisciplinar estabelecerá, junto das práticas ambientais e do desenvolvimento didático-pedagógico, a transmissão e reconstrução dos conteúdos disciplinares, experimentando a transformação do diferente em relação ao outro. A interdisciplinaridade não se trata de simples cruzamento de coisas parecidas, trata-se de Constituir e Construir diálogos fundamentados na diferença, amalgamando concretamente a riqueza da diversidade.

Segundo Brasil 1999, o trabalho interdisciplinar precisa "partir da necessidade sentida pelas escolas de explicar, compreender, intervir, mudar, prever, algo que desafia uma disciplina isolada e atrai a atenção de mais de um olhar, talvez, vários". Todavia, contar com a interdisciplinaridade na educação básica é um tanto desafiador devido a dificuldade de associar os conteúdos disciplinares de outras disciplinas ou até mesmo torna-las relacionadas entre si, porém, no ponto de vista pedagógico a interdisciplinaridade proporciona a integração dos conhecimentos vistos em sala, promovendo uma melhor compreensão e otimizando processo de ensino-aprendizagem do estudante (BONATTO, et al, 2012).

No entanto, segundo Moura 2017, apesar de terem conhecimento acerca da importância de aulas interdisciplinares muitos professores não estão preparados para trabalhar interdisciplinarmente, isso devido a falta de instrução em programas de formação continuada ou habilidades para fazer a conexão entre os conteúdos e demais disciplinas ou até mesmo por faltar recursos para utilizar nas aulas. 


\section{O PROFESSOR E O ENSINO DA EDUCAÇÃO AMBIENTAL NA ESCOLA}

No Brasil em 1981 é defendida a criação da Política Nacional do Meio Ambiente, que situa a EA como um dos princípios que garantem a "preservação, melhoria e recuperação da qualidade ambiental propícia à vida, visando assegurar no país condições ao desenvolvimento sócio econômico, aos interesses da segurança nacional e à proteção da dignidade da vida humana" em 1987 foi aprovada a inclusão da EA nos currículos escolares brasileiros de $1^{\circ}$ e $2^{\circ}$ graus (DAHLEM e BRAGA, 2009).

Muitas ações e eventos de preservação do meio ambiente e sustentabilidade surgiram com o passar dos anos, e com a conferência de Estocolmo, em 1972, surgiu a necessidade de se educar para preservar, inserindo a EA como ferramenta da prática pedagógica. $O$ governo brasileiro então: insere a EA na educação formal por meio de aprovação dos Parâmetros Curriculares Nacionais (PCN) em 1997, retratam os conteúdos a serem trabalhados publicada com a Lei $\mathrm{n}^{\circ}$ 9.795/99, implementada com o decreto ํㅜ 4.281/02, criando o órgão Gestor da Educação Brasileira congregando os Ministérios da Educação e do Meio Ambiente (DAHLEM e BRAGA, 2009).

O ensino da EA nas escolas vai além da condição de preservar o meio ambiente, o conceito de educar para a sustentabilidade tem um componente educativo formidável: a preservação do meio ambiente depende de uma consciência ecológica e a formação da consciência depende da educação, pois esta possibilita ampliar conhecimentos, mudança de paradigma, ressignificando valores, posturas, buscando aperfeiçoar habilidades, priorizando a integração e harmonia dos indivíduos com o meio ambiente (GADOTTI, 2009).

A Educação Ambiental, de acordo com DIAS (1994), se caracteriza por incorporar as dimensões sociais, políticas, econômicas, culturais, ecológicas e éticas, o que significa que ao tratar de qualquer problema ambiental, devem-se considerar todas as dimensões. Ou seja, são diversos pontos que envolvem a discussão da EA e todas as esferas 
citadas anteriormente precisam ser levadas ao centro da problematizarão para um completo entendimento de nossas ações no meio.

Tendo em vista que o orientador e o facilitador desse conhecimento é o professor, cabe a ele desenvolver metodologias para o ensino da EA nas escolas, com enfoque em particular no ensino médio, fase onde o pensar crítico tem inicio. Há nessa caminhada alguns obstáculos a serem encarados e traspassados pelo professor. Neste contexto, o grande desafio dos profissionais de educação quanto à temática ambiental é possibilitar ao aluno desenvolver habilidades necessárias para a compreensão do papel do homem na natureza, pois somente assim o aluno poderá se reconhecer como organismo e, portanto, sujeito aos mesmos processos e fenômenos que os demais. Ele também deve se reconhecer como agente capaz de modificar ativamente o processo evolutivo, alterando a biodiversidade e as relações estabelecidas entre os organismos" (BRASIL, 2006).

Dessa forma, para uma melhor atuação dos profissionais da educação é sem dúvida o investimento na formação inicial que aborda essa temática de forma defasada, e continuada dos professores, a participação em eventos, palestras e encontros de aprimoramento profissional é essencial para que a prática docente no ensino da EA tome rumos mais concretos (MELO, 2009).

\section{EDUCAÇÃO AMBIENTAL E PROPOSTA CTSA (CIÊNCIA, TECNOLOGIA, SOCIEDADE E AMBIENTE).}

Diante dos avanços tecnológicos e científicos, Vasconcelos e Santos 2008 destaca a importância de instruir os alunos quanto essas questões que interferem em grande massa na sociedade atual. Pra ressaltar a importância da temática socioambiental teve início a proposta CTSA, uma abordagem que surgiu como uma crítica aos avanços tecnológicos e científicos que resultaram na exploração e consequências negativas ao meio ambiente, como a degradação ambiental. A proposta CTSA ganha espaço na área pedagógica aproximando o aluno do objeto de estudo cientifico, tornando a aprendizagem significativa e instigante. 
Estas são abordagens que envolvem o cotidiano dos estudantes e promove reflexões que estimulam o senso crítico dos alunos levando-os a repensar diversas esferas como social, econômica, cultural e política. Destaca-se a importância de envolver estes alunos nessas problemáticas e possibilitar o uso da tecnologia para fazer ciência e contribuir na sustentabilidade do planeta (BOURSCHEID, 2014). Considerando a EA e abordagem CTSA como propostas que visam formar cidadãos conscientes, destacamos a sua importância em estar inserido no ambiente escolar.

\section{METODOLOGIA}

A presente ação foi desenvolvida em menção ao dia do meio ambiente, no dia 5 de junho. Com base nisso, os bolsistas do Programa Institucional de Bolsa de Iniciação à Docência (PIBID) de Biologia juntamente ao supervisor, realizaram o planejamento da Semana do Meio Ambiente com um olhar interdisciplinar articulando os temas relativos ao meio ambiente com as disciplinas curriculares da instituição de ensino correspondente, Colégio Dom Agostinho lkas da UFRPE.

Visando a atividades lúdicas e didáticas para uma melhor compreensão e participação do corpo estudantil, foi proposto a realização de palestras, rodas de conversas, oficinas, mesa redonda e experimentos. Outro meio utilizado foi a apresentação de documentários oriundos do projeto de extensão da instituição escolar, chamado CineBio que promove a exibição de vídeos e filmes que contribuem na aprendizagem significativa dos estudantes.

As ações foram realizadas com temas relativos à ecologia, preservação, sustentabilidade, consumo consciente e reciclagem, em associação com as disciplinas curriculares da instituição escolar, como sociologia, biologia, química, inglês e geografia.

\begin{tabular}{|l|l|l|}
\hline ATIVIDADE & PROCEDIMENTO & DISCIPLINA \\
\hline Mesa redonda - & Os professores abordaram o tema & Sociologia, \\
Consumo e & conforme a perspectiva de cada disciplina. \\
poluição & $\begin{array}{l}\text { Sociologia (consumo) Biologia (impactos } \\
\text { do consumismo no meio ambiente) }\end{array}$ & \\
\hline
\end{tabular}




\begin{tabular}{|c|c|c|}
\hline & $\begin{array}{lll}\text { Química } & \text { (composição } & \text { química } \\
\text { materiais jogados no lixo). }\end{array}$ & \\
\hline $\begin{array}{l}\text { Palestra - } \\
\text { Agrotóxicos }\end{array}$ & $\begin{array}{l}\text { Ministração de palestra sobre os riscos } \\
\text { que os agrotóxicos podem trazer para o } \\
\text { homem e o meio ambiente }\end{array}$ & $\begin{array}{l}\text { Curso técnico em } \\
\text { agropecuária }\end{array}$ \\
\hline $\begin{array}{l}\text { Roda de } \\
\text { conversa - } \\
\text { Impactos do } \\
\text { consumismo no } \\
\text { meio ambiente }\end{array}$ & $\begin{array}{l}\text { Apresentação de um documentário (na } \\
\text { disciplina de inglês o vídeo estava nesse } \\
\text { idioma). Logo após os alunos puderam } \\
\text { discutir acerca da problemática } \\
\text { apresentada. }\end{array}$ & Inglês e sociologia \\
\hline $\begin{array}{l}\text { Palestra - } \\
\text { Plásticos nos } \\
\text { recursos hídricos }\end{array}$ & $\begin{array}{l}\text { Exibição de vídeos e ministração de } \\
\text { palestra sobre o surgimento dos plásticos, } \\
\text { sua importância e impactos nos rios e } \\
\text { oceanos. }\end{array}$ & Geografia \\
\hline $\begin{array}{l}\text { Oficina dos } \\
\text { recicláveis }\end{array}$ & $\begin{array}{l}\text { As turmas se dividiram em grupos para } \\
\text { fazer jogos didáticos com materiais } \\
\text { recicláveis. Os grupos tiveram três dias } \\
\text { para montar seus jogos, e expor para } \\
\text { outros alunos e professores, o melhor jogo } \\
\text { em aspecto de aprendizado foi premiado } \\
\text { com uma caixa de bombons. }\end{array}$ & $\begin{array}{l}\text { Biologia, no } \\
\text { entanto os jogos } \\
\text { possuíam } \\
\text { conteúdos de } \\
\text { variadas } \\
\text { disciplinas. }\end{array}$ \\
\hline
\end{tabular}

\section{RESULTADOS}

A realização da semana do meio ambiente foi de grande valia para a formação docente dos bolsistas do PIBID, mas também para todo corpo estudantil. A utilização de recursos audiovisuais e discussões durante as palestras, oficinas e mesas redondas proporcionaram reflexões e 0 despertar do senso crítico dos alunos de forma a contribuir com a formação de cidadãos que atuam para conservação e consequente melhoria das condições caóticas que se encontra nosso planeta.

Durante as palestras os alunos visualizavam as consequências provenientes da ação humana no meio ambiente, ou seja, eram colocados em situações problemas, que de acordo com Castro, et al (2017), uma forma de promover uma fixação dos assuntos abordados e participação da turma é através da metodologia da problematizarão, em que coloca os alunos em situações problemas estimulando o cognitivo e o senso crítico dos estudantes, proporcionando um ambiente de socialização e exposição de ideias. 
Entendemos que a partir da experiência vivenciada pelos alunos e pela comunidade escolar em geral, houve uma maior conscientização quanto a preservação e aos cuidados que o homem quanto ser que produz e consome deve atribuir ao meio ambiente, tendo em vista o enfoque metodológico atribuído a semana do meio ambiente através das ações com o caráter CTSA.

\section{CONSIDERAÇÕES FINAIS}

Com base no conteúdo exposto no trabalho, verifica-se que a utilização da temática de educação ambiental inserida no ambiente escolar pode contribuir na formação de cidadãos críticos e participativos no que se refere às questões ambientais e à manutenção da qualidade de vida em diversos ambientes. Tendo em vista que para haver resultados significativos quanto à aprendizagem dos alunos é necessário um engajamento pleno e contínuo na execução de ações de cunho ambiental como também capacitação efetiva dos profissionais da educação e apoio de toda comunidade escolar.

No mais, a educação ambiental contribui na aprendizagem significativa dos estudantes podendo estar atrelada com as demais disciplinas curriculares do ensino básico de forma transversal e interdisciplinar sendo possível que o aluno realize associações do conteúdo com seu dia a dia.

\section{REFERÊNCIAS}

BRASIL. Ministério da Educação. Secretaria de Educação Média e Tecnológica. Parâmetros Curriculares Nacionais: Ensino Médio. Brasília: Ministério da Educação,1999.

BRASIL. Ministério da Educação. Secretaria de Educação Continuada, Alfabetização e Diversidade. Educação na diversidade: o que fazem as escolas que dizem que fazem educação ambiental? Brasília: MEC/SECAD, 2006. 
BONATTO, Andréia; BARROS, Caroline Ramos; GEMELI, Rafael Agnolleto; LOPES, Tatiana Bica; FRISON, Marli Dallagnol. Interdisciplinaridade no ambiente escolar. IX ANPED SUL, Seminário da pesquisa em educação na região sul, 2012.

BOURSCHEID, Jacinta Lourdes Weber; FARIAS Maria Eloisa. A convergência da educação ambiental, sustentabilidade, ciência, tecnologia e sociedade (CTS) e ambiente (CTSA) no ensino de ciências. Revista Thema, 2014.

COIMBRA, Audrey de Souza. Interdisciplinaridade e educação ambiental: interligando seus princípios necessários. 2005.

CONRADO, Luana Mayra Nunes; Silva, Victor Hugo da. R. gest. sust. ambient., Florianópolis, v. 6, n. 3, p. 651-665, out./dez. 2017.

CASTRO, Elton Anderson Santos de; RODRIGUES, Jadir Gonçalves; BESSA, Sônia. Aplicação da metodologia de problematização. EDUCERE III Congresso Nacional de Redução pág. 20224-20236,2017.

DAHLEM, R. B; BRAGA, R. Desenvolvimento Sustentável: Reflexões Conceituais e sua Materialização no Espaço. Cascavel - PR. Anais do I Seminário Internacional de (CTS).28 a 30 de abril de 2009.

DIAS, Genebaldo Freire. Educação Ambiental: princípios e práticas. São Paulo, Global, 1994.

GADOTTI, Moacir. Educar para a Sustentabilidade. São Paulo: Instituto Paulo Freire, 2009.

MELO, Adriana Silva; MONTES, Silma Rabelo; LIMA, Luís de. Educação ambiental em cursos de formação continuada para docentes do ensino básico - Uberlândia (MG) EM EXTENSÃO, Uberlândia, v. 8, n. 1, p. 48 59, jan./jul. 2009.

MOURA, Wilson Antônio Lopes de; MOURA, Maria Samara Lopes Almeida de; FESTUCCI, Victória Beatriz Marega; BONZANINI, Taitiâny Kárita; FERNANDEZ, Fernanda da Rocha Brando. Interdisciplinaridade e 
o ensino de ciências: o professor compreende essa relação?XI Encontro Nacional de Pesquisa em Educação em Ciências - XI ENPEC, 2017.

PELICIONI, Maria Cecília Focesi. Educação Ambiental, qualidade de vida e Sustentabilidade. Saúde e sociedade 7(2):19-31, 1998.

ROOS, Alana; BECKER, Elsbeth Leia Spod. Educação Ambiental e Sustentabilidade. Revista Eletrônica em Gestão, Educação e Tecnologia Ambiental REGET/UFSM , v(5), n5, p. 857 - 866, 2012.

VASCONCELOS, Erlete Sathler de; SANTOS, Widson Luiz P. dos. Educacao ambiental por meio de tema CTSA: realato e analise de experiencia em sala de aula. XIV Encontro Nacional de Ensino de Quimica, Curitiba/PR, 21 a 24 de junho de 2008. 